\title{
An open multicenter study of polyacrylamide hydrogel (Bulkamid®) for female stress and mixed urinary incontinence
}

\author{
Gunnar Lose • Helle Christina Sørensen • \\ Susanne M. Axelsen • Christian Falconer • \\ Kurt Lobodasch • Tosson Safwat
}

Received: 28 January 2010 /Accepted: 22 June 2010 /Published online: 20 July 2010

(C) The Author(s) 2010. This article is published with open access at Springerlink.com

\begin{abstract}
Introduction Polyacrylamide hydrogel (PAHG, Bulkamid ${ }^{\circledR}$ ) is a promising urethral bulking agent. This multicenter study was carried out to evaluate safety and efficacy of Bulkamid ${ }^{\circledR}$ for female stress and mixed urinary incontinence.

Methods Submucosal injection of Bulkamid ${ }^{\circledR}$ was performed in 135 women with urinary incontinence (stress, 67; mixed, 68) followed for 12 months. Forty-seven had a reinjection (35\%).

Results At 12 months, the subjective response rate was $66 \%$. Incontinence episodes $/ 24 \mathrm{~h}$ and urine leakage $\mathrm{g} / 24 \mathrm{~h}$ decreased significantly (from 3.0 to 0.7 and $29 \mathrm{~g}$ to $4 \mathrm{~g}$, respectively). Additionally, the median International Consultation on Incontinence Questionnaire score was reduced to approximately $50 \%$, and the overall quality of life visual
\end{abstract}

G. Lose $(\varangle) \cdot$ H. C. Sørensen

Department of Obstetrics and Gynaecology,

Herlev County Hospital, University of Copenhagen,

Herlev Ringvej 75,

DK-2730 Herlev, Denmark

e-mail: gulo@heh.regionh.dk

S. M. Axelsen

Aarhus University Hospital,

Skejby, Denmark

C. Falconer

Division of Obstetrics \& Gynaecology Danderyd Hospital,

Karolinska Institutet,

Stockholm, Sweden

K. Lobodasch

DRK Hospital Chemnitz-Rebenstein,

Chemnitz, Germany

T. Safwat

University Hospital of Hartlepool,

Hartlepool, UK analogue scale score was decreased significantly (from 72 to 20). Efficacy was very similar between patients with stress and mixed incontinence. Thirty treatment-related adverse events were registered. The most frequent was urinary tract infection $(n=10)$. No polyacrylamide hydrogel-specific adverse events were seen.

Conclusions Bulkamid ${ }^{\circledR}$ is an effective and safe bulking agent in women with stress or mixed incontinence.

Keywords Bulking · Polyacrylamide hydrogel · Stress · Mixed incontinence

\section{Introduction}

Intramural urethral bulking therapy for female urinary incontinence has become increasingly popular among physicians and patients due to its minimally invasive nature. Recent advances have shed light on the working mechanism of bulking agents [1], and a recent clinical study has documented that bulking therapy is more effective than conservative treatment in terms of pelvic floor training [2].

Many agents of different make and tissue interaction have been used for urethral bulking. However, in terms of efficacy, no clear conclusions can be drawn from trials comparing alternative agents at the moment [3]. Safety concerns have been raised with regard to specific agents because of migration [4], hypersensitivity [5], urethral erosion [6], pseudocysts/abscess [7], and granuloma formation [8-11]. Materials such as paraffin, polytetrafluroethylene, autologous fat, and most recently, ethylene vinyl alcohol (Tegress $\left.{ }^{\circledR}\right)$ and hyaluronic acid/dextranomer copolymer (Zuidex ${ }^{\circledR}$ ) have been abandoned because of safety issues.

In 2006, polyacrylamide hydrogel (PAHG) Bulkamid ${ }^{\circledR}$ was introduced in Europe as a promising new urethral 
bulking agent [12]. It is a polymer gel consisting of $2.5 \%$ cross-linked polyacrylamide and $97.5 \%$ water for injection, which is atoxic $[13,14]$ and resistant to degradation $[15$, 16]. It has a widespread use in ophthalmic surgery, drug treatment, food packaging, and water purification [17]. PAHG has been used in plastic surgery for esthetic purposes in the former Soviet Union and China for the past 15 to 20 years, and in Europe for the past 7 [18]. According to these studies, the gel stays within soft tissues for at least $81 / 2$ years after the injection, and gives rise to little or no tissue reaction without capsular fibrosis or calcification [15]. A recent study in rabbits has shown that the bulking effect is preserved for at least for 7 months [13], and a study in pigs has documented that PAGH is a stable viscoelastic bulking agent which is being integrated within its host tissue by vessel ingrowth [16].

The aim of the present study was to investigate the clinical efficacy and safety of PAHG (Bulkamid $\left.{ }^{\circledR}\right)$ in a larger cohort of women with stress or mixed urinary incontinence.

\section{Materials and methods}

The study was an open, noncomparative, multicenter, and multinational study including 10 centers in five countries; two centers in Denmark, two in Sweden, one in Finland, four in UK, and one in Germany. The study was performed in accordance with International Conference on Harmonisation Good Clinical Practice Guidelines.

Methods, definitions, and units conform to the standards recommended by the International Continence Society, except where specifically noted [19].

\section{Patient characteristics}

Women aged $\geq 18$ years were eligible to participate if they had symptomatic stress or mixed incontinence for $\geq 12$ months, and $\geq 1$ incontinence episode per $24 \mathrm{~h}$, measured by a 3-day micturition diary. Additional requirements were a maximum flow rate of $\geq 15 \mathrm{ml} / \mathrm{s}$, a post-void residual urine volume (PVR) of $\leq 100 \mathrm{ml}$, a bladder capacity $\geq 300 \mathrm{ml}$ based on the micturition diary (measured over 3 days) normal diuresis $(<40 \mathrm{ml} / \mathrm{kg}$ per $24 \mathrm{~h})$, and no pelvic organ prolapse $\geq$ stage 2 .

Women were excluded if they had an acute urinary tract infection (UTI), allergic reaction to local anesthesia and antibiotics used for prophylaxis, had previous surgery for incontinence including bulking, received ongoing medication for incontinence (except anticholinergics at a constant dose for $>4$ weeks), were treated with systemic corticosteroids, or suffered from active autoimmune or connective tissue diseases, or were pregnant.

All women had a screening visit including full medical history, a physical and pelvic examination including genital prolapse (pelvic organ prolapse quantification) score, uroflowmetry, PVR measurement, and urine dipstick test (if positive with culture and sensitivity). The screening visit was followed by a baseline visit collecting data from the 24$\mathrm{h}$ pad-weighting test and estimating bladder capacity, number of micturitions, stress and urge incontinence episodes; diuresis were estimated based on a 3-day micturition diary. In addition, the International Consultation on Incontinence Questionnaire (ICIQ) [20], as well as a patient quality of life (QoL) visual analogue scale (VAS) score [21] was filled in. Treatment with PAHG was performed at the baseline visit or within 3 days, and no later than 8 weeks from the screening visit. In case of a UTI at the baseline visit, a new baseline visit could be rescheduled one time.

\section{Treatment and follow-up}

The PAHG injection was administered under local anesthesia. The women were in the lithotomy position, and a total of $10 \mathrm{ml}$ of $5 \%$ Lidocaine was injected into the wall of the urethra at 3 and 9 o'clock positions. PAHG was injected transurethrally into the submucosa under urethroscopic control using a $23 \mathrm{G} \times 120$-mm needle with $1 \mathrm{~cm}$ markings to enable correct placement of the injection (Bulkamid ${ }^{\circledR}$ cystoscope, Fig. 1).

Two or three deposits $(0.2-0.8 \mathrm{ml}$ each) were placed $0.5-1 \mathrm{~cm}$ distal to the bladder neck at 2, 6, and 10 o'clock positions. The needle was re-sited if the injection appeared

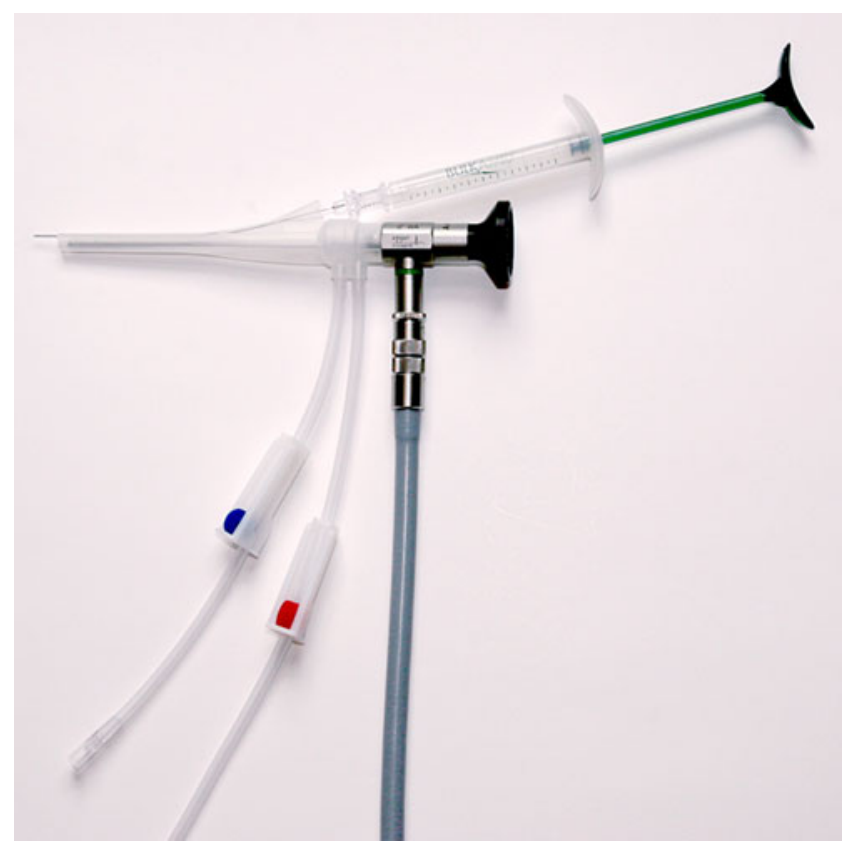

Fig. 1 The Urethroscope, connected to the rotatable sheath, with inflow/outflow tubings. The needle $(23 \mathrm{G} \mathrm{x} 12 \mathrm{~cm})$ is placed in the working-canal connected to a $1 \mathrm{ml}$ syringe with Bulkamid 
to be too superficial, too deep, or if there was extravasation of PAHG into the bladder or urethral lumen. After satisfactory urethral occlusion, the bladder was emptied via the endoscope. During injection, the women received a prophylactic antibiotic treatment, e.g., an i.v. dose of cefuroxime $(1.5 \mathrm{~g})$. They were discharged after successful voiding (PVR $<100 \mathrm{ml}$, assessed by ultrasonography).

The women were reevaluated 1,6 , and 12 months later. The efficacy assessment included patient subjective perception ("cured", "improved", "not changed", or "worsened") [22]), number of incontinence episodes/24 h, 24-h pad-weighting testing, ICIQ, and VAS score on QoL. Furthermore, urine stix were performed, and measurement of PVR was carried out.

Patients considering themselves for "cured" or "improved" were defined as responders. If they had not gained satisfactory benefit from the first injection at the first-month follow-up visit, they were offered a second treatment within 8 weeks period.

Adverse events were classified as serious or non-serious, and judged to be either related (ADE) or unrelated to the study treatment $(\mathrm{AE})$.

\section{Data analyses and statistics}

The sample size was estimated based on a binomial distribution. Assuming a success rate of PAHG treatment of at least $50 \%$ with a maximum of uncertainty of $10 \%$, the trial should include a minimum of 100 patients. Assuming a dropout rate of $20 \%$, a total of 125 subjects should be enrolled into the study.

All analyses were based on the intention-to-treat (ITT) analysis set, which was defined as patients that have received at least one PAHG injection.

The subjective responder rate at 6 and 12 months was estimated using a logistic regression with time as fixed effect. Change from baseline in the ICIQ scores was analyzed by the Wilcoxon signed-rank test. Each of the three ICIQ questions, as well as their total sum score, was analyzed separately. Urine leakage (pad test) was analyzed in an ANOVA model with time as fixed effect. Number of incontinence episodes was evaluated in a generalized linear model for repeated measurements assuming a Poisson distribution and a covariance matrix with compound symmetry structure. Estimated changes from baseline are presented as ratios (estimate postbaseline compared to baseline). Three VAS scores measuring QoL as a result of overall incontinence, stress incontinence, or urge incontinence were analyzed separately in an ANOVA model with time and baseline VAS score as fixed effects. PVR, the proportion of subjects receiving a second injection of PAHG, duration of the injection procedure, and the surgeons' satisfaction with the injection technique were summarized using descriptive statistics.
Missing values were imputed with the last observation carried forward (LOCF) in the analyses of the responder rate and ICIQ. For repeated measurements, missing values were not imputed with the LOCF. Instead, they were dealt with inside the model. Repeated measurement analyses were performed for urine leakage (pad test), incontinence episodes, and QoL parameters.

Additional analyses Additional analyses were performed to evaluate the effect of other variables in the treatment outcome. Responder rate was assessed on data sets stratified by: type of urine incontinence (stress versus mixed), number of treatments (one vs two), and number of PAGH injection procedures performed per center $(<15$ injections (low volume) versus $\geq 15$ injections (high volume)). Analyses were based on a logistic regression model with missing responder values imputed with LOCF. As supportive analysis of the primary analysis, the logistic regression model was expanded by incorporating the covariates age and BMI as continuous variables, in separate analyses.

Ethical assurances The study was conducted in accordance with the Declaration of Helsinki II 1964, as amended in Scotland, October 2000, the Council Directive 93/42/EEC of 14 June 1993 concerning medical devices (commonly known as the Medical Device Directive), and the international ISO standard ISO/DIS 14155-1+2:2003 clinical investigation of medical devices for human subjects. The clinical investigation plan was submitted to all local ethics committees. Written informed consent was obtained from all patients after written and verbal information about the study, procedures, potential risks, or inconveniences, and expected benefits.

\section{Results}

One hundred thirty-five women (67 with stress and 68 with mixed incontinence) were recruited and treated with PAHG. Table 1 outlines the patients' demographic and baseline measurements.

Ninety-eight patients completed the study, 36 withdrew, and one patient failed to attend only the 12 months follow-up visit. One patient withdrew due to an AE (aggravated urine incontinence), 11 due to insufficient effect, and six due to protocol violations. Three patients were lost to follow-up, three withdrew their informed consent, and 12 withdrew for other reasons.

The ITT analysis set included 135 patients, and the per protocol analysis set included 94 patients (four of the 98 patients who completed the study had protocol violations, but were allowed to continue in the safety analyses of the study). 
Table 1 Demographic and incontinence-related characteristics of the ITT population at baseline

Demographic and baseline measurements $(N=135)$

\begin{tabular}{|c|c|c|}
\hline & Median & Range \\
\hline Age (years) & 56 & $29-82$ \\
\hline Weight (kg) & 76 & $54-106$ \\
\hline BMI $\left(\mathrm{kg} / \mathrm{m}^{2}\right)$ & 27 & $20-40$ \\
\hline Length of incontinence (years) & 6 & $1-39$ \\
\hline Maximal urine flow $(\mathrm{ml} / \mathrm{s})$ & 28 & $15-87$ \\
\hline Daily diuresis per $\mathrm{kg}(\mathrm{ml} / \mathrm{kg} / 24 \mathrm{~h})$ & 23 & $9-78$ \\
\hline Bladder capacity (ml) & 500 & $250-1,200$ \\
\hline PVR (ml) & 20 & $0-100$ \\
\hline
\end{tabular}

The median of total injected volume of PAHG per treatment was $1.5 \mathrm{ml}$ (range $0.8-3 \mathrm{ml}$ ). The median volume per deposit was $0.5 \mathrm{ml}$.

\section{Efficacy}

Responder rates (cured/improved) after 1 month, 6 months, and 12 months were $87 \%, 71 \%$, and $66 \%$, respectively. The corresponding fractions of totally cured patients were $27 \%$, $16 \%$, and $24 \%$, respectively. At 12 months, 19 patients were categorized as non-responders, 17 showed "nochange", and two worsening of symptoms. The subjective responder rate at 12 months was $70 \%$ among patients with stress incontinence compared to $63 \%$ among those with mixed incontinence. The responder rate at 12 months was higher among those receiving one treatment than among receiving two $(71 \%$ vs $57 \%, p=0.0058)$. The responder rate after 12 months was $58 \%$ among women treated at a low volume center ( $<15$ injections), and $69 \%$ among those treated at a high volume center ( $\geq 15$ injections). This difference is of borderline statistical significance $(p=0.0974)$.

No significant relationships could be found between the responder rate and age, $\mathrm{BMI}$, or injected $\mathrm{PAGH}$ volume.

The median ICIQ score (three questions shown in Table 2) decreased by approximately $50 \%$ at 1,6 , and 12 months follow-up $(p<0.0001)$. The overall QoL VAS score decreased significantly from a baseline median of 72 to 19,22 , and 20 after 1 month, 6 months, and 12 months follow-up, respectively. The corresponding stress component score was improved from a baseline median of 81 to 18,22 , and 18, and the urge component score from a baseline median of 40 to 9,7 , and 6 after 1, 6, and 12 months, respectively.

The median number of incontinence episodes/24 h decreased in the group as a whole from 3.0 (range 0.0-14.7) at baseline to 0.7 (range $0.0-16.0$ ) at 1 month, 6 months, and 12 months ( $p<0.0001$ vs baseline). In $72 \%$ of the patients, number of incontinence episodes decreased by at least $50 \%$. The median number of stress episodes decreased from 1.3 (range 0-8) at baseline to 0.0 (range 0.0-13.0) at 12 months, while the median number of urge incontinence episodes decreased from 0.7 (range $0.0-8.7$ ) at baseline to 0.0 (range $0.0-7.7)$ at 12 months.

The median urine leakage/ $24 \mathrm{~h}$ was significantly reduced after treatment in the group as a whole, ranging from $29 \mathrm{~g}$ (range 1-552) at baseline to $4 \mathrm{~g}$ (range 0-347) at 1 month, $5 \mathrm{~g}$ (range $0-150$ ) at 6 months, and $4 \mathrm{~g}$ (range $0-144$ ) at 12 months $(p<0.0001$ vs baseline). Thus, the urine leakage/24 $\mathrm{h}$ was reduced by approximately $85 \%$, and $69 \%$ of the patients had at least $50 \%$ decrease in urine leakage.

The median PVR was unchanged during the study (baseline $20 \mathrm{ml}$ (range 0-100), 1 month, $8 \mathrm{ml}$ (range 0-158), 6 months, $12 \mathrm{ml}$ (range 0-116), and 12 months, $11 \mathrm{ml}$ (range 0-131)).

The total number of injections was 182 , as 47 out of the 135 patients $(35 \%)$ received $\mathrm{PAHG}$ reinjections.

The injection procedure took a median time of $7 \mathrm{~min}$ (range 2-20 $\mathrm{min}$ ).

Surgeon satisfaction with the injection procedure was 82 (range 34-100), as measured by VAS of $100 \mathrm{~mm}$.

\section{Safety}

Of the 135 patients, 59 experienced an AE. The total number of events were 96 , of which 88 were non-serious AEs (57 patients), and eight were serious (eight patients). Out of 88 non-serious AEs, 32 were classified as possibly (19), or probably (11) related to the treatment (Table 3).

Table 2 Medians of the ICIQ scores at baseline, 1, 6, and 12 months follow-up in the ITT analysis set

\begin{tabular}{|c|c|c|c|c|}
\hline Question & Baseline & 1 month & 6months & 12 months \\
\hline How often do you leak urine? (range $0-5$ ) & 4.0 & 1.0 & 2.0 & 2.0 \\
\hline How much urine do you usually leak? (range $0-6$ ) & 4.0 & 2.0 & 2.0 & 2.0 \\
\hline How much does leaking urine interfere with your everyday life? (range $0-10$ ) & 8.0 & 2.0 & 3.0 & 3.0 \\
\hline Total (range $0-21$ ) & 15.0 & 6.0 & 70 & 7.0 \\
\hline
\end{tabular}

All scores were significantly decreased at all follow-up visits $(p<0.0001)$ 
Table 3 Summary of the 32 reported treatment-related adverse events which occurred after 182 injections

\begin{tabular}{lc}
\hline Adverse events & No. of occurrences \\
\hline UTI & 10 \\
Injection site pain & 5 \\
Urinary retention & $2^{\mathrm{a}}$ \\
Voiding difficulties & $2^{\mathrm{b}}$ \\
Past void residual $>100 \mathrm{ml}$ & $2^{\mathrm{c}}$ \\
Haematuria & 2 \\
Urine incontinence aggravated & 2 \\
De novo urge incontinence & 2 \\
Injection site laceration & 1 \\
Headache & 4 \\
\hline${ }^{\mathrm{a}}$ Classified as serious due to hospitalization, recovered within 6 and \\
9 days, respectively \\
${ }^{\mathrm{b}}$ Not catheterized \\
${ }^{\mathrm{c}}$ Catheterized 2 and 4 times within 3 days, respectively
\end{tabular}

Out of the 32 treatment-related AEs were 10 cases of UTI, nine with postprocedural pain, two of urinary retention, two of transurethral catheterization, two of hematuria, two of aggravated incontinence, two of de novo urge incontinence, and one of injection-site rupture. Two out of eight serious AEs were treatment-related. Both of them were urinary retention, which had resolved within 6 and 9 days, respectively.

\section{Discussion}

This study has shown that the subjective and objective outcome at 12 months was similar to that shown in a previous study of 25 women with stress or mixed urine incontinence who had been injected with PAGH [12], taking into account that the present results are based on ITT analysis. Not surprisingly, the outcome was consistent in those with pure stress incontinence compared to those with mixed incontinence. Our results are also comparable to reports in the literature on bulking agents $[23,24]$ and recently published article on Bulkamid [25].

However, this study also showed that patients, who were treated at centers conducting fewer bulking procedures, appeared to have a poorer outcome than those treated at centers conducting higher amount of bulking procedures. This indicates that there is a learning curve for mastering injection therapy via an endoscope. Median injection time was $7 \mathrm{~min}$, emphasizing the ease of the procedure, albeit performed under direct urethroscopic guidance.

Approximately 1/3 (35\%) of the patients received a second injection within the first 8 weeks comparable to other studies $[23,24]$. Remarkably, we found a significantly lower cure rate among those patients who received two treatments, indicating poor effect after the first injection as a risk factor.

We made no attempts to differentiate between pathophysiologic factors such as hypermobility and/or intrinsic sphincter deficiency, as clinical efficiency following bulking does not seem to differ among these subgroups [26]. Our study comprised daily routine patients who had only been treated with noninvasive urodynamic procedures.

However, the right patient population for urethral injection treatment is still being disputed. Clinical data show that patients have a general preference for less invasive forms of therapy, and they are willing to trade a lower success rate in favor of less invasive procedures [27]. However, pretreatment counseling of the patient is important for the clarification of the patient's expectations in terms of efficacy and safety.

Polyacrylamide is a polymer made of repeated units of acrylamide monomers, which are bound covalently by strong single bonds. This means that the original hazardous nature of the acrylamide monomer is no longer present. The linear chain structure of the polymer has further been folded into a three-dimensional entanglement in principal forming one huge single and very stable molecule. The total amount of residual acrylamide monomer in the PAGH Bulkamid is less than $1 \mathrm{mcg} / 1-\mathrm{ml}$ product. This amount is lower than normal daily intake of acrylamide with food and drinking water. By PAGH injection, the human body is exposed to a single dose of hardly measurable amount of acrylamide, and as the molecule is resistant to degradation [28], no subsequent acrylamide monomer is to be expected.

Acrylamide is classified as a potential carcinogenic substance since it was shown to induce cancer in rodents. However, since no conclusive connection was proven even between intake of high doses of acrylamide and cancer [29, 30], there is no scientific evidence to suspect PAGH being carcinogenic.

PAHG seems to have many of the ideal properties of a bulking agent [31]. It does not contain microparticles, which are shown to provoke a foreign body reaction and give rise to fibrosis and calcifications, and is highly biocompatible, not evoking hypersensitivity or granuloma formation. It also exerts a favorable anatomical integrity by allowing invasion of macrophages and giant cells that are gradually replaced by a thin, vessel-bearing fibrous network $[15,16]$.

The volume of some of the other more common bulking agents may reduce significantly with time [32]. $\mathrm{PAGH}$, in the opposite, remains stable in volume for years [15], most likely due to a constant exchange of its water molecules with those of surrounding tissue extracellular matrix. [33].

In this study, the material was injected in the upper third of the urethra, but a recent study seems to indicate that the 
bulking effect can be improved by injecting into the mid urethral zone [34].

The median amount of PAHG injected per treatment was $1.5 \mathrm{ml}$, which is similar to what has been reported previously [12]. This is however significantly less than commonly reported from other materials [24]. Too much material injected per site may increase the risk of material leakage, either via the injection hole, or due to rupture, or necrosis of the covering mucosa. No clear standard exists for the optimal relationship between amount of injected material and cure rate [24].

PAHG can be visualized ultrasonographically enabling monitoring during the injection procedure. This is a significant advantage especially in case of reinjection, but also in case of material retraction, if too much material has been injected (author's personal experience).

PAHG therapy did not change PVR, indicating no influence on bladder emptying. This is in accordance with previously reported pressure-flow data [12].

All AEs were generic and not related to the material. The most common AE (10/182 injections) was UTI, despite the use of prophylactic antibiotics. Eight patients experienced problems with bladder emptying-all transient and possibly due to the injection of the local anesthetic along the urethra and hence, interference with its afferent activity. Removal of injected material was not necessary in any case, and specific injection site or product-specific AEs were not found, suggesting a high safety profile of the material.

This study confirms that approximately two out of three women with uncomplicated stress or mixed incontinence can be improved or cured by PAHG injection therapy, and that the results sustain for at least 1 year postoperatively. The procedure is quick and easy to perform and therefore, well accepted by the physician. The PAGH safety profile seems unique, as no injection site or product-specific AEs were seen.

Acknowledgements This study was supported by Contura International A/S, Sydmarken 23, DK-2860 Soeborg, Denmark. However, Contura International $\mathrm{A} / \mathrm{S}$ cannot be held responsible for opinions expressed by the authors of this report.

Funding The trial was sponsored by Contura International A/S (Sydmarken 23, DK-2860 Soeborg, Denmark), which also provided the Bulkamid ${ }^{\circledR}$ for the trial.

Conflicts of interest G. Lose: paid travel expenses or honoraria, payment for research, consultancy (Contura, Johnson\&Johnson, Pfizer, Coloplast, Novartis). H.C. Sorensen: none. S. Axelsen: paid travel expenses or honoraria, consultancy (Astellas). C. Falconer: paid travel expenses or honoraria, payment for research, consultancy (Johnson\&Johnson, Pfizer, Astellas). K. Lobodasch: consultancy (Johnson\&Johnson) S. Tosson: none.
Open Access This article is distributed under the terms of the Creative Commons Attribution Noncommercial License which permits any noncommercial use, distribution, and reproduction in any medium, provided the original author(s) and source are credited.

\section{References}

1. Klarskov N, Lose G (2008) Urethral injection therapy: what is a mechanism of action? Neurourol Urodyn 8:789-92

2. ter Meulen PH, Berghmans LC, Nieman FH, van Kerrebroeck PE (2009) Effects of macroplastique implantation system for stress urinary incontinence and urethral hypermobility in women. Int Urogynecol J Pelvic Floor Dysfunct 20:177-183

3. Keegan PE, Atiemo K, Cody J, McClinton S, Pickard R (2007) Periurethral injection therapy for urinary incontinence in women. Cochrane Database Syst Rev CD003881

4. Henly DR, Barrett DM, Weiland TL, O'Connor MK, Malizia AA, Wein AJ (1995) Particulate silicone for use in periurethral injections: local tissue effects and search for migration. J Urol 153:2039-2043

5. Stothers L, Goldenberg SL (1998) Delayed hypersensitivity and systemic arthralgia following transurethral collagen injection for stress urinary incontinence. J Urol 159:1507-1509

6. Hurtado E, McCrery R, Appell R (2007) The safety and efficacy of ethylene vinyl alcohol copolymer as an intra-urethral bulking agent in women with intrinsic urethral deficiency. Int Urogynecol J Pelvic Floor Dysfunct 18:869-873

7. Hagemeier T, Blau U, Gauruder-Burmester A, Tunn R (2006) Paraurethral abscess developing after mid-urethral Zuidex-injection in women with stress urinary incontinence-management of complications and retrospective comparison with bladder neck located injection technique. Zentralbl Gynäkol 128:68-70

8. Castillo-Vico MT, Checa-Vizcaino MA, Paya-Panades A, RuedaGarcia C, Carreras-Collado R (2007) Periurethral granuloma following injection with dextranomer/hyaluronic acid copolymer for stress urinary incontinence. Int Urogynecol J Pelvic Floor Dysfunct 18:95-97

9. Madjar S, Sharma AK, Waltzer WC, Frischer Z, Secrest CL (2006) Periurethral mass formations following bulking agent injection for the treatment of urinary incontinence. J Urol 175:1408-1410

10. Bedir S, Kilciler M, Ozgok Y, Deveci G, Erduran D (2004) Longterm complication due to dextranomer based implant: granuloma causing urinary obstruction. J Urol 172:247-248

11. Palma PC, Riccetto CL, Martins MH, Herrmann V, de Fraga R, Billis A et al (2006) Massive prolapse of the urethral mucosa following periurethral injection of calcium hydroxylapatite for stress urinary incontinence. Int Urogynecol J Pelvic Floor Dysfunct 17:670-671

12. Lose G, Mouritsen L, Nielsen JB (2006) A new bulking agent (polyacrylamide hydrogel) for treating stress urinary incontinence in women. BJU Int 98:100-104

13. Bello G, Jackson IT, Keskin M, Kelly C, Dajani K, Studinger R et al (2007) The use of polyacrylamide gel in soft-tissue augmentation: an experimental assessment. Plast Reconstr Surg 119:1326-1336

14. Zarini E, Supino R, Pratesi G, Laccabue D, Tortoreto M, Scanziani E, Ghisleni G, Paltrinieri S, Tunesi G, Nava M (2004) Biocompatibility and tissue interactions of a new filler material for medical use. Plast Reconstr Surg 114:934

15. Christensen LH, Breiting VB, Aasted A, Jorgensen A, Kebuladze I (2003) Long-term effects of polyacrylamide hydrogel on human breast tissue. Plast Reconstr Surg 111:1883-1890

16. Christensen LH, Nielsen JB, Mouritsen L, Sorensen M, Lose G (2008) Tissue integration of polyacrylamide hydrogel: an experimental study 
of periurethral, perivesical, and mammary gland tissue in the pig. Dermatol Surg 34(Suppl 1):S68-S77

17. Smith EA, Oehme FW (1991) Acrylamide and polyacrylamide: a review of production, use, environmental fate and neurotoxicity. Rev Environ Health 9:215-228

18. Pallua N, Wolter TP (in press) A 5 year assessment of safety and aesthetic results after facial soft-tissue augmentation with Polyacrylamide Hydrogel (Aquamid(C): A prospective multicenter study of 251 patients. PRS

19. Abrams P, Cardozo L, Fall M, Griffiths D, Rosier P, Ulmsten U et al (2002) The standardisation of terminology of lower urinary tract function: report from the Standardisation Sub-committee of the International Continence Society. Neurourol Urodyn 21:167-178

20. Avery K, Donovan J, Peters TJ, Shaw C, Gotoh M, Abrams P (2004) ICIQ: a brief and robust measure for evaluating the symptoms and impact of urinary incontinence. Neurourol Urodyn 23:322-330

21. Stach-Lempinen B, Kujansuu E, Laippala P, Metsanoja R (2001) Visual analogue scale, urinary incontinence severity score and 15 D-psychometric testing of three different health-related qualityof-life instruments for urinary incontinent women. Scand J Urol Nephrol 35:476-483

22. EMEA (2002) Note for guidance on the clinical investigation of medicinal products for treatment of urinary incontinence. CPMP/ EWP/18/01 final, 1-7. Directive 75/318/EEC

23. Chapple CR, Haab F, Cervigni M, Dannecker C, Fianu-Jonasson A, Sultan AH (2005) An open, multicentre study of NASHA/Dx Gel (Zuidex) for the treatment of stress urinary incontinence. Eur Urol 48:488-494
24. Smith A (2005) Surgery for urinary incontinence in women. In: Abrams P, Cardozo L, Khoury S, and Wein A, (eds). International Consultation on incontinence, pp 1319-1323

25. Lobodasch K (2010) Transurethral Injections with Bulkamid. Initial Clinical Results. Geburtshilfe Frauenheilkd 70:47-51

26. Chapple CR, Wein AJ, Brubaker L, Dmochowski R, Pons ME, Haab F et al (2005) Stress incontinence injection therapy: what is best for our patients? Eur Urol 48:552-565

27. Robinson D, Anders K, Cardozo L, Bidmead J, Dixon A, Balmforth $\mathrm{J}$ et al (2003) What Do Women Want?: Interpretation of the Concept of Cure. J Pelvic Med Surg 9:273-277

28. Caulfield MJ et al (2002) Some Aspects of the Properties and Degradation of Polyacrylamide. Chem Rev 102:3067-3083

29. International Agency for Research on Cancer (IARC) (1994) On-line summary of acrylamide evaluation. World Health Organization

30. Integrated Risk Information System (IRIS) (1993) Acrylamide. U. S. Environmental Protection Agency.

31. Appell RA, Dmochowski RR, Herschorn S (2006) Urethral injections for female stress incontinence. BJU Int 98(Suppl 1):27-30

32. Elzayat EA, Karsenty G, Bismar TA, Corcos J (2008) Volume changes and histological response to injected dextranomer/ hyaluronic acid copolymer (Zuidex) and collagen (Contigen) in rats. Int Urogynecol J Pelvic Floor Dysfunct 19:247-252

33. Brahm J, Lessel R, Ditlev S, Schmidt R (2008) Determination of water and solute transport in polyacrylamide gels. Macromol Symp 266:63-67

34. Kuhn A, Stadlmayr W, Lengsfeld D, Mueller MD (2008) Where should bulking agents for female urodynamic stress incontinence be injected? Int Urogynecol J Pelvic Floor Dysfunct 19:817-821 